\title{
Aleitamento Materno na Estratégia Saúde da Família (Esf): Percepções de Enfermeiros para uma Prática Humanizada
}

\author{
Araújo, Thiago Moura de; Silva, Roberta Alves da; Costa, Ana Cristina P. de J.; \\ Vieira, Neiva Francenely da C.; Araújo, Marcio Flavio M. de \\ Universidade Internacional da Integração da Lusofonia Afro-Brasileira (Unilab) - \\ thiagomouraenf@yahoo.com.br
}

Introdução: o aleitamento materno é reconhecido em todo o mundo como uma das principais estratégias para a promoção da saúde da criança, entretanto os índices ainda estão abaixo do esperado, tal situação pode ser justificado pelo surgimento de dificuldades no período de aleitamento. Objetivos: o presente estudo objetivou analisar a percepção de enfermeiros da ESF sobre a prática do aleitamento materno para uma prática humanizada. Método: Estudo qualitativo, realizado em sete Unidades Básicas de Saúde do município de Imperatriz - MA, com nove enfermeiros, entre julho e setembro de 2013. Aplicou-se entrevista semi-estruturada, contemplando variáveis sociodemográficos, de conhecimento e da assistência de enfermagem oferecida no aleitamento materno. o estudo teve aprovação do Comitê de Ética em Pesquisa da Universidade Federal do Maranhão conforme protocolo no 000530/2011-40. Resultados: Os principais resultados evidenciaram que os enfermeiros possuem conhecimento a respeito do aleitamento materno, embora as atualizações fornecidas pelos gestores sobre a temática sejam insuficientes, costumam abordar a temática do aleitamento tanto no pré-natal como nas consultas puerperais, no entanto, não há sistematização da assistência à lactante que apresenta dificuldades para o aleitamento materno. em relação às percepções dos enfermeiros sobre aleitamento materno, verifica-se a predominância do conceito de Aleitamento Materno Exclusivo e a sua importância para a saúde da criança e construção do binômio mãe-bebê como prática humanizada. Os enfermeiros participantes referiram informações distintas a respeito da realização de capacitação na temática aleitamento materno, onde foi possível observar que alguns referiram não possuir capacitação contínua, e outra parcela dos investigados relatou frequência em capacitações na temática. Conclusão: o estudo conclui que os enfermeiros procuram intervir ao perceberem que a lactante decide interromper o processo de amamentação mediante alguma dificuldade vivenciada. Todavia a assistência de enfermagem destinada a estas dificuldades é realizada de forma não sistematizada, sem contemplar a prevenção e a elaboração de um plano de cuidados individualizado.

Araújo, Thiago Moura de; Silva, Roberta Alves da; Costa, Ana Cristina P. de J.; Vieira, Neiva Francenely da C.; Araújo, Marcio Flavio M. de. Aleitamento Materno na Estratégia Saúde da Família (Esf): Percepções de Enfermeiros para uma Prática Humanizada. In: Anais do Congresso Internacional de Humanidades \& Humanização em Saúde [= Blucher Medical Proceedings, num.2, vol.1]. São Paulo: Editora Blucher, 2014. ISSN 2357-7282

DOI 10.5151/medpro-cihhs-10817 